Abstract 117 Table 1 Prevalence of severe CAD in stable chest pain and ACS patients according to age and sex

\begin{tabular}{|l|c|c|c|}
\hline $\begin{array}{l}\text { Stable chest pain } \\
\text { group }\end{array}$ & Total no. of patients & No. of patients with severe CAD & \% with severe CAD \\
\hline Females aged $<55$ & 37 & 5 & $14 \%$ \\
\hline Females aged $>55$ & 120 & 30 & $25 \%$ \\
\hline Males aged $<55$ & 46 & 13 & $28 \%$ \\
\hline Males aged $>55$ & 127 & 51 & $40 \%$ \\
\hline Total & 330 & 99 & \\
\hline
\end{tabular}

\begin{tabular}{|l|c|c|c|}
\hline ACS group & Total no. of patients & No. of patients with severe CAD & \% with severe CAD \\
\hline Females aged $<55$ & 14 & 3 & $21 \%$ \\
\hline Females aged $>55$ & 96 & 49 & $51 \%$ \\
\hline Males aged $<55$ & 26 & 14 & $54 \%$ \\
\hline Males aged $>55$ & 114 & 72 & $63 \%$ \\
\hline Total & 250 & 138 & \\
\hline
\end{tabular}

\section{CEASEFIRE! REMEMBER TO CHECK THE LDL. A RETROSPECTIVE AUDIT OF HYPERLIPIDAEMIA MANAGEMENT FOLLOWING ACUTE CORONARY SYNDROMES}

${ }^{1}$ Handi Salim*, ${ }^{2}$ Kaung Lwin, ${ }^{3}$ Helen Routledge, ${ }^{3}$ Jasper Trevelyan, ${ }^{2}$ Chee Wah Khoo, ${ }^{3}$ David G Wilson. ${ }^{1}$ University Hospital Birmingham NHS Trust; ${ }^{2}$ University Hospital of North Midlands NHS Trust, ${ }^{3}$ Worcestershire Acute Hospitals NHS Trust

\subsection{6/heartjnl-2019-BCS.115}

Introduction Control of hypercholesterolaemia is a highly effective way of reducing cardiovascular events in patients at elevated risk of cardiovascular disease. Repeat cholesterol measurement is good practice in lipid management but is rarely performed in the modern era of statins with clinicians often adopting a 'fire and forget' policy to lipid management.

Following NICE approval of proprotein convertase subtisilin/kexin 9 inhibitor (PCSK9i), there is a need to identify patients who are eligible for this treatment. A retrospective audit was performed to determine our performance in lipid measurement 3-months following initiation of lipid therapy (CG181) and to determine whether all patients with an indication for a PCSK9i following ACS were being identified (TA393 and 394).

Methods We retrospectively evaluated in-hospital ACS patients using Myocardial Infarction National Audit Project (MINAP) registries at two active cardiac centres in West Midlands based at Worcester Acute Hospital Trust (January 2010 - December 2017) and Royal Stoke Hospital (January 2014 - December 2016). Patients with total cholesterol levels $7.2 \mathrm{mmol} / \mathrm{l}$ were selected as sample population. Total cholesterol and LDL levels were recorded during admission and post-discharge.
Previous polyvascular disease puts patients at very high risk category with lower LDL threshold required for PCSK9i $(>3.5 \mathrm{mmol} / \mathrm{L}$ instead of $>4.0 \mathrm{mmol} / \mathrm{L})$.

Results We identified $167 / 7048(2.4 \%)$ patients with a total cholesterol of $7.2 \mathrm{mmol} / \mathrm{L}$. Of these, eight patients died on admission. Mean age was 62 years (range 27-96 years), median cholesterol of $7.8 \mathrm{mmol} / \mathrm{L}$, and 33 patients $(20 \%)$ with previous polyvascular diseases. Overall 125 patients had repeat cholesterol level (79\%). LDL level was performed in 93 patients $(58 \%)$ on admission and repeated within 3 months post discharge (CG181) in 20 patients (13\%). Overall, 48 patients $(30 \%)$ had any repeat LDL recorded.

Of this group, 10 patients met the NICE TA393 and 394 criteria for PCSK9i; eight from Worcester and two from Stoke. This represents $0.14 \%$ of the total cohort.

Conclusion Failure to repeat LDL levels in patients following hospital discharge with a diagnosis of ACS, is likely to explain the small number of patients identified as being eligible for PCSK9i. We suspect that underreporting of co-morbid vascular disease within the MINAP database also contributed by preventing the identification of patients at very high risk. It is estimated that primary non-familial hypercholesterolaemia affects 4\% adult population in England (NICE TA393 committee papers). Of these, 28 out of 100,000 population may require PCSK9i treatment. We advocate ending the 'fire and forget' policy of lipid-monitoring and re-establishing the practice of routine repeat fasting lipids measurement following discharge from hospital in order to correctly identify all patients who may be eligible for optimal lipid lowering therapy.

Conflict of Interest nil 